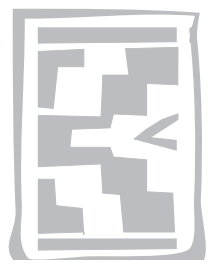

\title{
The systematic position of some Ethiopian Nippostrongylinae (Nematoda, Trichostrongylina, Heligmosomoidea) from the National Collection of Animal Helminths, Onderstepoort, South Africa
}

\author{
M.-C. DURETTE-DESSET ${ }^{1}$ and M.-C. DIGIANI ${ }^{2}$
}

\begin{abstract}
DURETTE-DESSET, M.-C. \& DIGIANI, M.-C. 2005. The systematic position of some Ethiopian Nippostrongylinae (Nematoda, Trichostrongylina, Heligmosomoidea) from the National Collection of Animal Helminths, Onderstepoort, South Africa. Onderstepoort Journal of Veterinary Research, 72: 55-65

The taxonomic status of some nippostrongyline nematodes deposited in the National Collection of Animal Helminths, Onderstepoort, is revised. Heligmonina boomkeri n. sp. is described from Aethomys chrysophilus from South Africa. The most closely related species by the body measurements and the pattern of the caudal bursa is Heligmonina bignonensis Diouf, Bâ \& Durette-Desset, 1997, a parasite of Mastomys erythroleucus from Senegal. It differs from the new species mainly in the number of ventral cuticular ridges at mid-body (four versus five) and the left ala in the male is shorter than the body diameter. The systematic position of Heligmonina spira (Ortlepp, 1939) and Neoheligmonella capensis (Ortlepp, 1939) is confirmed here through their synlophe, which was not previously studied.
\end{abstract}

Keywords: Ethiopian region, Heligmonina boomkeri n. sp., Heligmonina spira, Murinae, Nematoda, Neoheligmonella capensis, Nippostrongylinae, synlophe, Trichostrongylina

\section{INTRODUCTION}

The Nippostrongylinae (Heligmonellidae) are parasites of relatively recent appearance, during the Upper Miocene (Durette-Desset 1985). They may have spread throughout the world with the migrations of their hosts, the Muridae. The group lends itself particularly well to molecular studies, the hosts being easy to capture and not considered as rare species in need of protection. A phylogeny of the Trichostrongylina based on morphological features was proposed by Durette-Desset (1985).

1 Département de Systématique et Evolution, Muséum national d'Histoire naturelle, UMR 7138 associée au CNRS, CP 52, 61 rue Buffon, 75251 Paris cedex 05, France

2 División Zoología Invertebrados, Facultad de Ciencias Naturales y Museo, Universidad Nacional de La Plata, Paseo del Bosque s/n, 1900 La Plata, Argentina

Accepted for publication 28 September 2004-Editor
However, a comparison of the phylogenies of the Nippostrongylinae based on morphological and on molecular characters, such as the ITS 1 and ITS 2, has not been made. Before embarking upon this work, it was necessary to clarify the systematic position of some species in which the synlophe, the main character used for the determination of a species, is not known or was insufficiently described. This study concerns the species described by Ortlepp (1939) in South Africa.

\section{MATERIAL AND METHODS}

The specimens studied originated from the National Collection of Animal Helminths (NCAH), formerly known as the Onderstepoort Helminthological Collection. They are very fragile and, in some, the cuticle was damaged or separated from the body on cross-section. The state of preservation of the speci- 
mens determined the accuracy of our descriptions, as some features were hardly visible or were absent due to attrition. The nomenclature used for taxa above the family group is that of Durette-Desset (1985) and that for the structures of the caudal bursa is that of Durette-Desset \& Chabaud (1981). The cuticular ridges were numbered from left to right for the dorsal and ventral sides, both being delimited by the lateral fields which were always visible. The curve of the left ala is not included in the measurement of its length. Where necessary, this length is compared with the diameter of the body at the level of the lateral fields (Fig. 2A). All measurements are in micrometers except where otherwise stated. The measurements of the female paratypes of the new species are indicated in parentheses. The material of the new species is deposited in the $\mathrm{NCAH}$, Onderstepoort, South Africa and the Helminthological Collection of the Muséum national d'Histoire naturelle, Paris, France (MNHN). The nomenclature of the hosts is that of Musser \& Carleton (1993).

\section{IDENTIFICATION OF THE SPECIES}

\section{Heligmonina boomkeri n. sp.}

\section{TYPE MATERIAL}

Holotype male, allotype female, nine male and two female paratypes, access number MNHN $331 \mathrm{MQ}$

\section{Host}

Aethomys chrysophilus (De Winston, 1904) Muridae, Murinae

SITE

\section{Duodenum}

\section{GEOGRAPHIC ORIGIN}

Jonkershoek, Stellenbosch, South Africa

\section{VOUCHER MATERIAL}

One female, MNHN $332 \mathrm{MQ}$, a parasite of Rhabdomys pumilio vittatus from Jonkershoek, Stellenbosch, South Africa, coparasite of Neoheligmonella capensis (Ortlepp, 1939).

\section{GENERAL}

Very small nematodes, body curved along the ventral side, anterior end in one or two spirals. Position of nerve ring variable. Excretory pore situated within posterior quarter of oesophagus. Deirids at same level of or posterior to excretory pore (Fig. 1). Oesophagus about $10 \%$ of body length. Left ala longer than body diameter. Very short vestibule slightly longer than sphincter. Ratio of uterus length to body length less than $25 \%$.

\section{SYNLOPHE}

In both sexes the body bears continuous cuticular ridges, appearing just posterior to cephalic vesicle, except left dorsal ridge adjacent to lateral field (no. 1 in Fig. 1C) and disappearing $70 \mu \mathrm{m}$ anterior to caudal bursa in male (Fig. 1D). In the female, ventral ridges disappear at different levels between the infundibulum and vulva (Fig. 1E-G and 2D-G), dorsal ridges and left ala disappear at about $40 \mu \mathrm{m}$ from anus (Fig. $1 \mathrm{H}$ ). Number of ridges: in female, at level of oesophago-intestinal junction, 13 (left hypertrophied ala, six dorsal, six ventral) (Fig. 2C); in both sexes, at mid-body, 12 (left ala, six dorsal, five ventral) (Fig. 2A and B). At mid-body, double gradient of size, decreasing from left to right on ventral side and from right to left on dorsal side. In section, left ala longer than body diameter in male, shorter in female (Fig. 2A and B). At mid-body, absence of ridges on right, ventral-right quarter. At mid-body, axis of orientation directed from ventral right to dorsal left side and inclined at $70^{\circ}$ on sagittal axis in male, $65^{\circ}$ in female (Fig. $2 \mathrm{~A}$ and B).

\section{Holotype MALE}

Holotype male is $2.3 \mathrm{~mm}$ and 95 wide at mid-body, left ala included; cephalic vesicle, 48 long and 27 wide; nerve ring, excretory pore and deirids situated at 120, 205 and 215 from apex, respectively; oesophagus, 215 long (Fig. 1A).

Asymmetrical caudal bursa with left lateral lobe more developed and pattern of type 1-3-1 (rays 2 and 6 separating the first from common trunk of rays $2-6$ ) in right lobe and $1-4$ (ray 2 separating the first from common trunk of rays 2-6) in left lobe with tendency to type 1-3-1 (Fig. 2 I and J). Left lobe: ray 6 arising the first from common trunk of rays 3-6, then ray 3 . Ray 4 the most developed, thicker and slightly longer than ray 5 . Rays 4 and 5 distally divergent. Ray 6 short (Fig. 2I). Right lobe: ray 5 arising the first from common trunk of rays $3-5$. Rays 8 arising proximally on trunk of dorsal ray, left ray longer than right one. Dorsal ray divided into two branches at its proximal third, each branch giving rise to two small branches, rays 9 (external branches) longer than rays 10 (internal branches). 


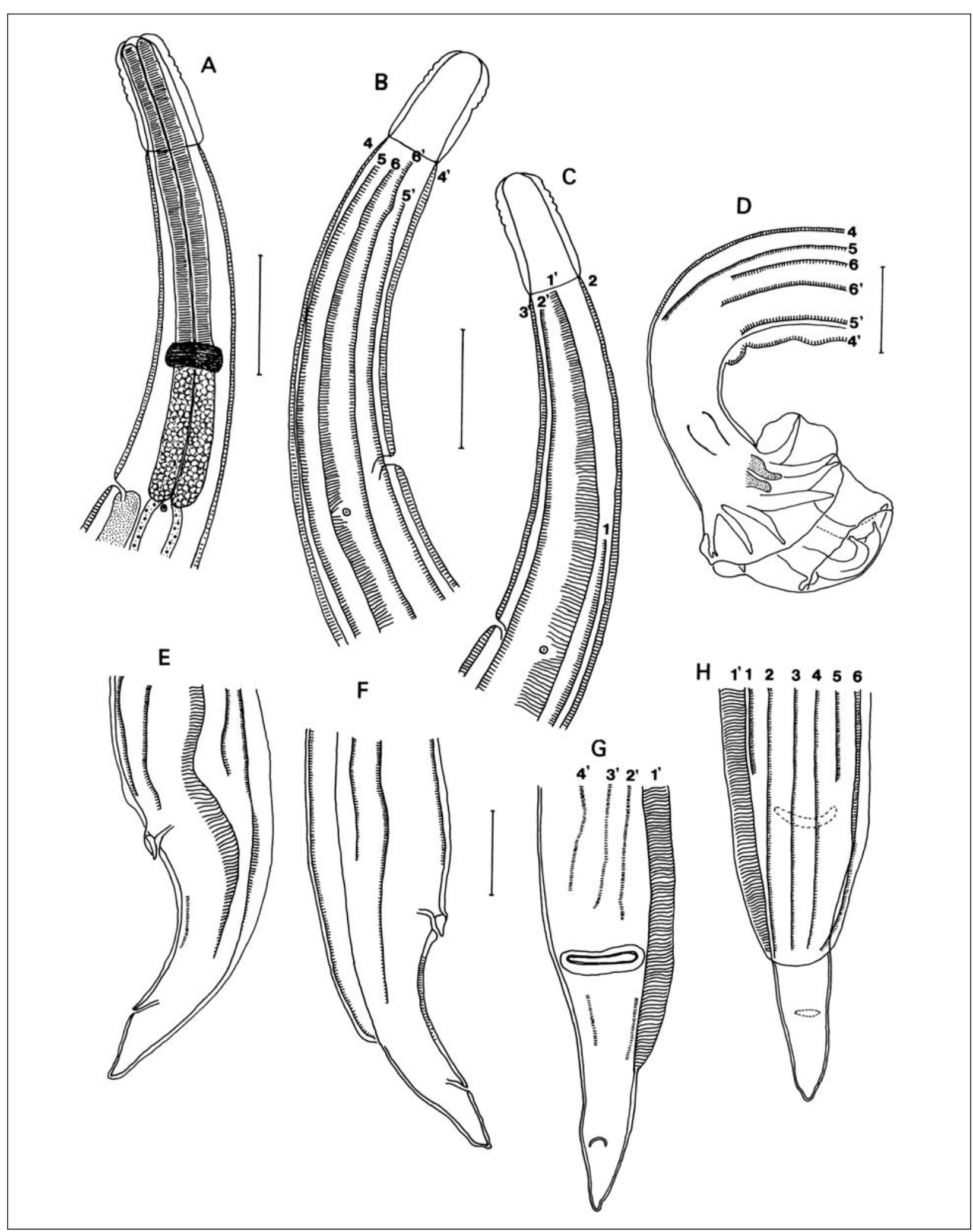

FIG. 1 Heligmonina boomkeri n. sp. A, male, anterior part, left lateral view. B, C, male, origin of the cuticular ridges, right and left lateral views. D-H, posterior part where the ridges disappear. D, male, right lateral view; $\mathrm{E}-\mathrm{H}$, female, $\mathrm{E}$, left lateral view, $\mathrm{F}$, right lateral view, $\mathrm{G}$, ventral view, $\mathrm{H}$, dorsal view

The ridges are numbered from left to right from no. $1-n$ for the dorsal side, no. $1^{\prime}-n$ ' for the ventral side

Scales: $50 \mu \mathrm{m}$ 


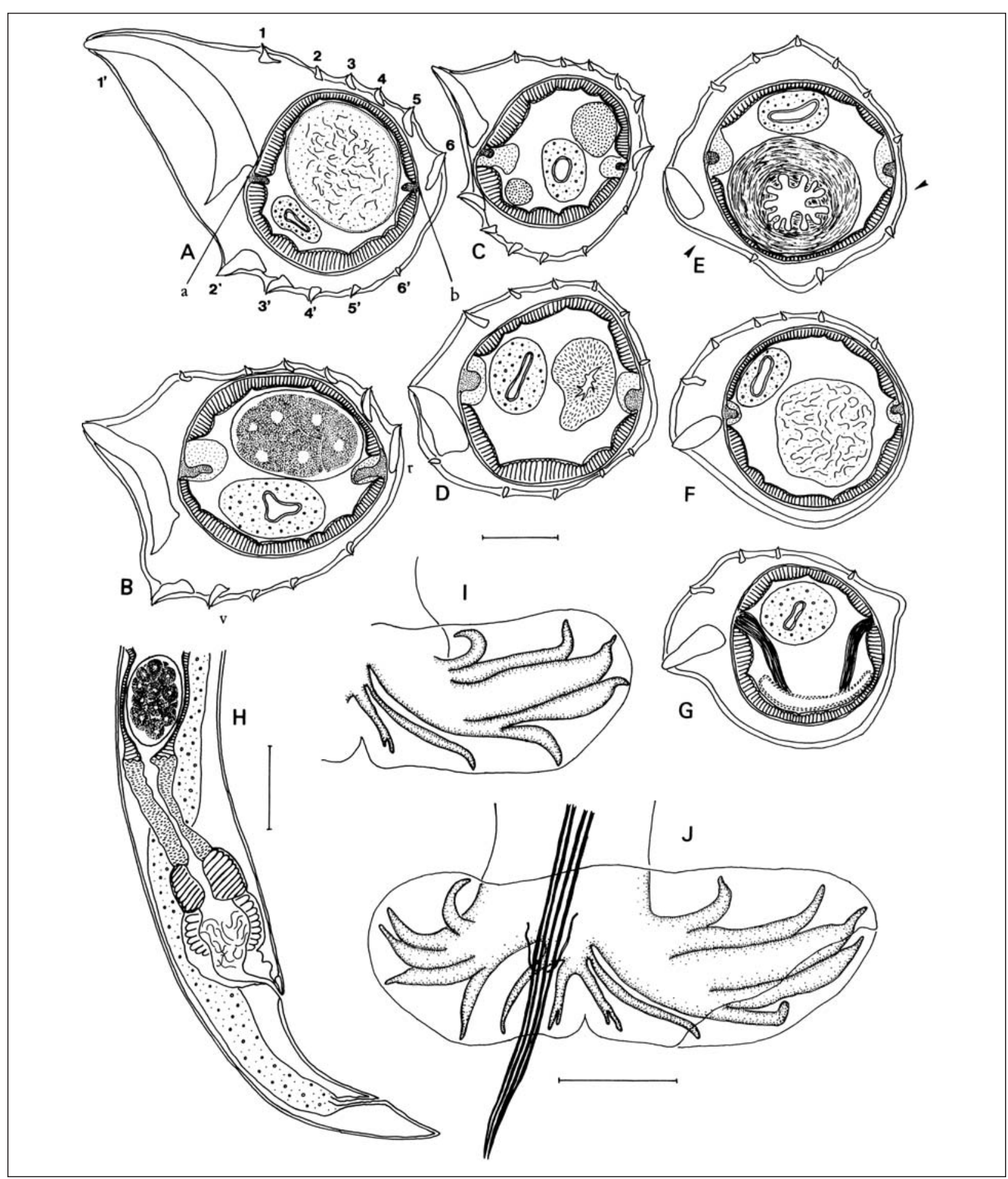

FIG. 2 Heligmonina boomkeri $\mathrm{n} . \mathrm{sp}$. A-G, synlophe in transverse sections of a male (2.65 $\mathrm{mm}$ long) and a female (3.1 $\mathrm{mm}$ long). A, male, at mid-body (900 $\mathrm{mm}$ from the apex); B-G, female, B, at mid-body (1.4 mm from the apex), C, at the oesophagointestinal junction, $\mathrm{D}$, at the level of the distal infundibulum, $\mathrm{E}$, at the level of the sphincter, $\mathrm{F}$, at the level of the distal vestibule, G, just posterior to the vulva. $\mathrm{H}$, female, posterior part, right lateral view. I, male, left lobe of the caudal bursa, ventral view. J, other male, caudal bursa, ventral view

The ridges are numbered from left to right from no. 1-6 for the dorsal side, no. 1'-6' for ventral side. The arrows indicate the disappearance of the ridges. All the ridges are orientated as in Fig. 2B

Abbreviations: $r$, right side, $v$, ventral side, ab: body diameter

Scales: A-G: $25 \mu \mathrm{m} ; \mathrm{H}-\mathrm{J}: 50 \mu \mathrm{m}$ 
Filiform, alate spicules, 418 long with sharp tips (Fig. 2J). Ratio of spicules length/body length: $18.4 \%$. Gubernaculum not distinct. In one specimen, a slight thickening of the cuticule of the spicular canal may represent this structure (Fig. 1D). Genital cone not visible (see below).

\section{MAIN MEASUREMENTS (AVERAGE AND RANGE) OF NINE PARATYPES}

Paratypes are 2.6 (2.0-3.0) mm long, 123 (100$150)$ wide at mid-body, left ala included; cephalic vesicle, 52 (46-60) long and 25.5 (21-30) wide; nerve ring $(n=8)$, excretory pore and deirids situated at 134 (120-160), 200 (180-240), 210 (180235) from apex, respectively; oesophagus 227 (200-260) long; spicules 406 (370-430) long; ratio spicules length/body length, 15.5 (15.1-17.6) \%; genital cone visible only in one paratype, 20 long and 18 wide.

\section{FEMALES (ALLOTYPE AND PARATYPES)}

Females are $3.9(3.4,3.1) \mathrm{mm}$ long and $95(100$, $90)$ wide; cephalic vesicle, $40(55,50)$ long and 23 $(20,25)$ wide; nerve ring, excretory pore and deirids situated at $140(160,130), 185(220,--)$ and 223 (230, --) from apex, respectively; oesophagus, 235 $(290,230)$ long.

Monodelphic. Vulva situated at $165(140,150)$ from caudal extremity. Vagina vera, $42(50,40)$ long. Ovejector $150(145,152)$ long with vestibule $50(50,55)$ long, sphincter $30(23,25)$ long and $45(40,50)$ wide, infundibulum $70(72,72)$ long. Uterus 550 $(740,700)$ long with $12(14,13)$ eggs, at morula stage, $63(60,57)$ long and $40(40,35)$ wide on average, arranged in one row. Tail $40(35,40)$ long with rounded extremity (Fig. $2 \mathrm{H}$ ).

\section{MAIN MEASUREMENTS OF THE FEMALE PARASITE FROM RHABDOMYS PUMILIO}

Female parasite is $3.5 \mathrm{~mm}$ long and 75 wide at midbody; cephalic vesicle, 54 long and 21 wide; nerve ring and excretory pore situated at 130 and 220 from apex, respectively; oesophagus 280 long; vulva situated at 160 from caudal extremity; ovejector 140 long; uterus 710 long with 13 eggs, 60 long and 40 wide; tail 58 long.

\section{REMARKS}

The specimens mentioned above were registered in the Onderstepoort collections as "Heligmonina stellenboschius Ortlepp, 1939", a parasite of $M y$ omys verroxii. Although the specimens from $A$. chrysophilus are close to the species described by Ortlepp (strong asymmetry of the lateroventral lobes of the caudal bursa, left ray 8 longer than the right one, gubernaculum not distinct), they are differentiated by the length of the left ala which is about half the body width and not two-thirds as in $\mathrm{H}$. stellenboschius. In addition, right rays 3 and 4 on the one hand and left rays 4 and 5 on the other are joined except at their distal extremity. The association of these two latter characters of the caudal bursa is present only in Heligmonina bignonensis Diouf, Bâ \& Durette-Desset, 1997, a parasite of Mastomys erythroleucus from Senegal which is the most closely related species by the body measurements and the pattern of the caudal bursa. Heligmonina bignonensis is differentiated by the more anterior position of the excretory pore, by the number of ventral cuticular ridges at mid-body (four versus five), by the left ala in the male being shorter than the body diameter, and by the length of left ray 6 being almost equal to that of ray 5 (approximately half the length of ray 5 in the specimens described above). We consider the specimens from Aethomys chrisophila as belonging to a new species which we have named Heligmonina boomkeri n. sp. in honour of our colleague, Prof. Joop Boomker.

\section{Heligmonina spira (Ortlepp, 1939) Durette-Desset, 1971}

= Heligmospiroides spira Ortlepp, 1939; = Longistriata ortleppi Desset, 1964

\section{STUDIED MATERIAL}

Two males, three females syntypes

HOST

Rhabdomys pumilio vittatus (Wagner, 1842) Muridae, Murinae

SITE

Duodenum

\section{GEOGRAPHIC ORIGIN}

Jonkershoek, Stellenbosch, South Africa

\section{GENERAL}

Small nematodes, tightly curved along their ventral side, following four spires in male, four to five in female. In posterior part of female, body curved along dorsal side and vulva and anus open at external side of body. Excretory pore situated within pos- 


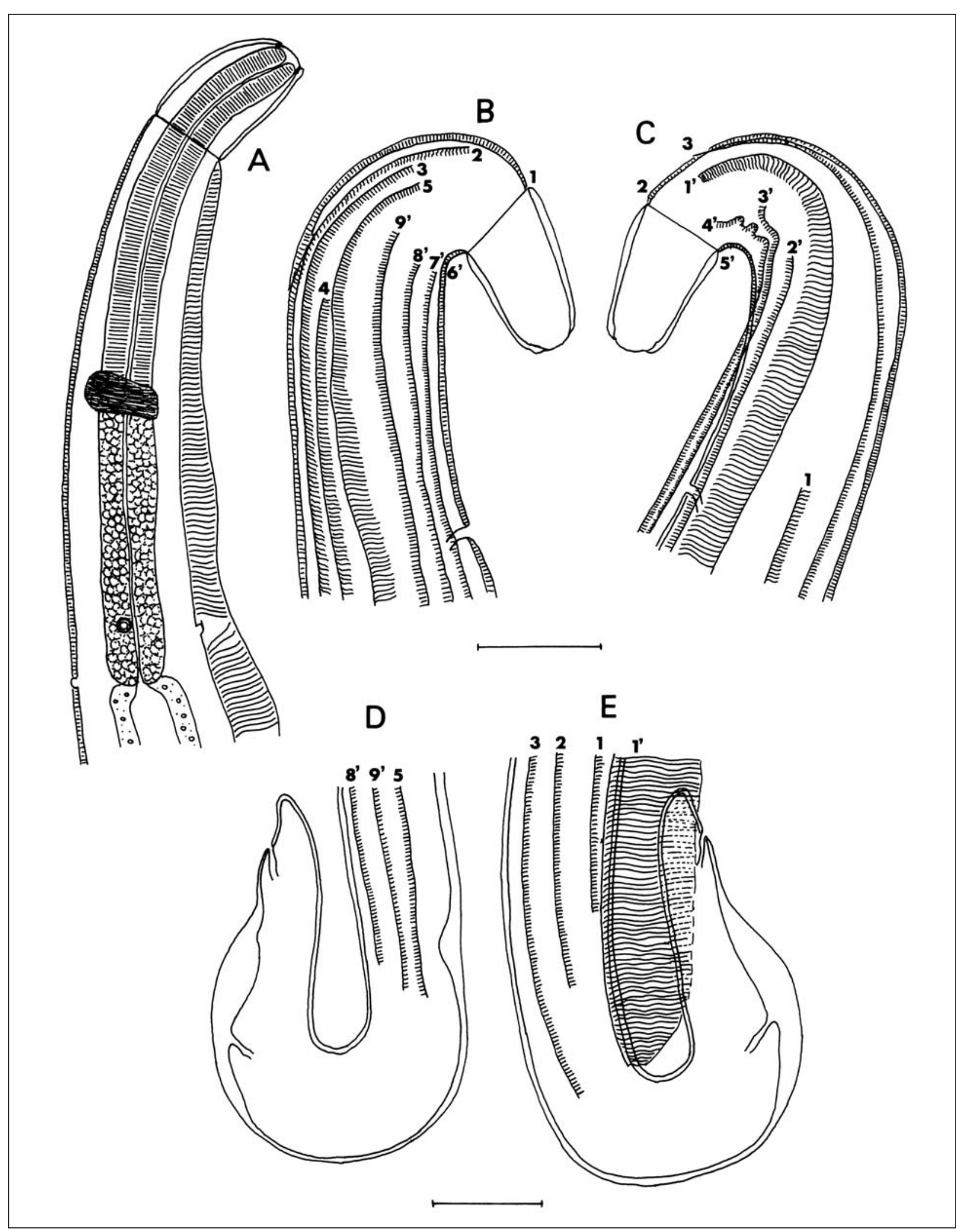

FIG. 3 Heligmonina spira (Ortlepp, 1939). A, male, anterior part, ventral view. B, C, female, origin of the ridges, right and left lateral views. D, E, female, area where the ridges disappear, right and left lateral views

The ridges are numbered from left to right, no. $1-n$ for the dorsal side, no. 1'- $n$ ' for the ventral side

Scales: A-C: $50 \mu \mathrm{m}$; D, E: $100 \mu \mathrm{m}$ 
terior third of oesophagus. Deirids at same level or posterior to excretory pore (Fig. 3A). Oesophagus less than $7 \%$ of body length in male, $6 \%$ in female. In male and female, left ala shorter than body diameter. Vestibule twice as long as sphincter. Ratio of uterus length/body length less than $20 \%$. Eggs in two rows except in distal part of the uterus.

\section{SYNLOPHE}

In both sexes, the body bears continuous cuticular ridges, appearing between the cephalic vesicle and excretory pore (Fig. 3B and C), except ridges no. 6 and 10' which appear posterior to it. Ridges disappear anterior to caudal bursa in male. In female, ridge no. 8' disappears at about 800 anterior to vulva (Fig. 4C), ridges no. 1 and 7' at about 300 anterior to vulva (Fig. 4D), other ridges at different levels between infundibulum and sphincter (Fig. 3D and E). The left hypertrophied ridge disappears at about 250 from vulva (Fig. 3E). Number of ridges at mid-body: 16 (left ala, six dorsal, nine ventral) in male (Fig. 4A), 15 (left ala, six dorsal, eight ventral) in female (Fig. 4B). Dorsal gradient of size, decreasing from left to right. At mid-body, on ventral side, gradient gradually decreasing from ridge no. 2'-5' in male, from no. 2'-4' in female, then ridges of equivalent size. Left ala almost as long as body diameter in both sexes. Presence of ridges on right, right-ventral quarter at mid-body (Fig. 4A-D). Axis of orientation at mid-body directed from right ventral to left dorsal side and inclined on sagittal axis at $60^{\circ}$ in both sexes (Fig. 4A and B).

\section{MALES}

Males are 4.3, $4.4 \mathrm{~mm}$ long and 70, 65 wide at midbody, left ala included; cephalic vesicle, 55, 50 long and 27, 35 wide; nerve ring and excretory pore situated at 160,150 and 265, -- from apex, respectively; deirids observed only in first male, situated at 270 (left deirid), 285 (right deirid) from apex; oesophagus, 290, 280 long (Fig. 3A).

Asymmetrical caudal bursa with left lateral lobe more developed and pattern of type 1-4 (rays 2 separating the first from common trunk of rays 2-6) (Fig. 4F). Very long rays 3 . Rays 3 and 6 arising at same level from common trunk of rays 3-6. Rays 4 and 5 joined in two thirds of their length (right lobe), divergent only at their extremities (left lobe). Rays 8 arising asymmetrically on trunk of dorsal ray. Dorsal ray divided into two branches at its distal quarter, each branch giving rise to two small equal branches, rays 9 (external branches) and rays 10 (internal branches) (Fig. 4F).
Spicules filiform, with sharp tips. It was not possible to measure the spicules and gubernaculum accurately. Very small genital cone, 15 long and 10 wide at base with papilla 0 and papillae 7 well developed (Fig. 4G).

\section{FEMALES}

Females are 5.9, 5.7, $6.2 \mathrm{~mm}$ long and 135, 140, 150 wide at mid-body, left ala included; cephalic vesicle, 60, 55, 50 long and 38, 35, 40 wide; nerve ring, excretory pore and deirids situated at 140, 160,$130 ; 185,220$, -- and 223, 230, -- from apex, respectively; oesophagus, 235, 290, 230 long.

Monodelphic. Vulva situated at 215, 210, 230 from caudal extremity. Vagina vera, 60, 55, 60 long. Ovejector 258, 210, 245 long with vestibule 80, 70, 70, sphincter 40, 30, 35 long and 45, 40, 45 wide, infundibulum 138, 110, 140 long, twisted at proximal part $(n=2)$. Uterus 1100, 950, 950 long with $25,22,30$ eggs at morula stage, 73 long by 43 wide on average, arranged in two rows. Tail $35,40,40$ long with rounded extremity (Fig. 4E).

\section{REMARKS}

The specimens described above are parasites of Rhabdomys pumilio and were named Heligmospiroides spira by Ortlepp (1939). The characters of the synlophe, not previously described in transversal sections, allows us to confirm that the species belongs to the genus Heligmonina, as proposed by Durette-Desset (1971). In comparing our findings with the detailed description of Ortlepp, we found some differences that we consider as minor, namely that the body and various organs are longer. It is interesting to note that, among the species of the genus, the female of $H$. spira is the only one in which the anus and the vulva open on the external side of the spire. According to the description of Ortlepp (1939) the male is the only one to have a very complex gubernaculum.

\section{Neoheligmonella capensis (Ortlepp, 1939) Durette-Desset, 1971}

= Longistriata $($ L.) capensis Ortlepp, 1939

\section{STUDIED MATERIAL}

Two males, two females syntypes, coparasites of Heligmonina boomkeri n. sp.

\section{Host}

Rhabdomys pumilio vittatus (Wagner, 1842) Muridae, Murinae 

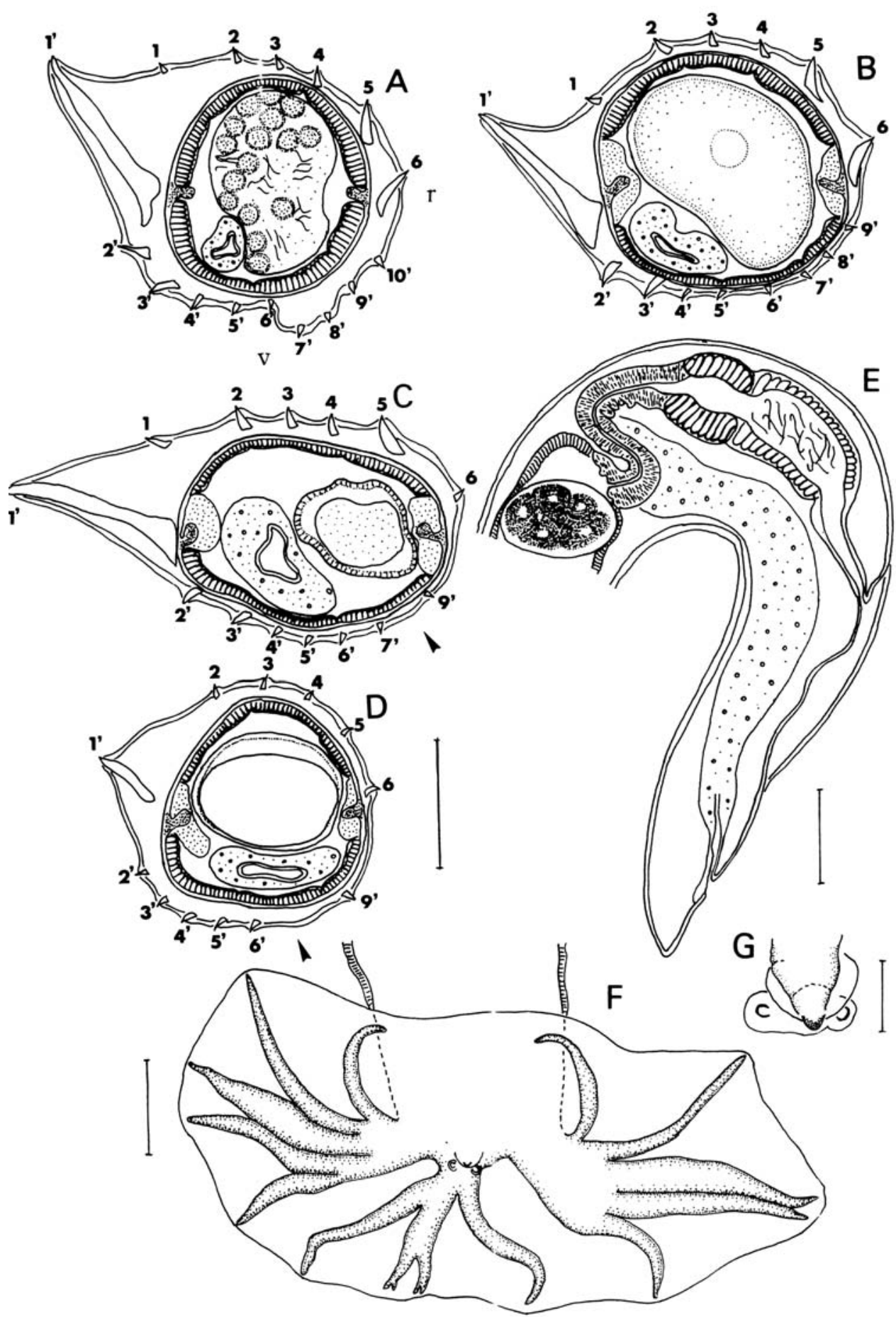
SITE

\section{Duodenum}

\section{GEOGRAPHIC ORIGIN}

Jonkershoek, Stellenbosch, South Africa

\section{GeNERAL}

Small nematodes, tightly curved along their ventral side. Excretory pore situated within posterior third of oesophagus. Deirids at same level than excretory pore (Fig. 5A). Oesophagus less than $10 \%$ of body length in male, $6 \%$ in female. In male and female, left ala twice as shorter as the body diameter. Vestibule twice longer than sphincter with constriction at middle. Ratio uterus length/ body length less than $20 \%$. Eggs in two rows except in distal part of uterus.

\section{SYNLOPHE}

In both sexes, the body bears continuous cuticular ridges, appearing just posterior to cephalic vesicle, except dorsal ridge of carene (no. 1) which appears at level of excretory pore. In male, ridges disappear anterior to caudal bursa except ridge no. 4 which disappears within posterior quarter of body (Fig. $5 \mathrm{E})$. In female, dorsal ridges no. 4 and 5 merge at about 400 anterior to vulva. All ridges disappear at level of vulva. Carene with dorsal ridge poorly developed in both sexes, except at the end of the anterior third in male (Fig. 5). Ridge no. 5 (in front of right lateral field) well developed. Number of ridges at oesophageal region (Fig. 5B) and at mid-body (5D and F): 12 (carene, four dorsal, six ventral) in both sexes; in female, at level of infundibulum, 11 (carene, three dorsal, six ventral) (Fig. 5G); just anterior to vulva: 6 (two dorsal, two left and two right lateral) (Fig. 5H). At mid-body, double gradient of size of the ridges. On ventral side, gradient gradually decreasing from left to right, from ridge no. $2 '-5$ ' then ridges of equivalent size. On dorsal side, except dorsal ridge of carene, gradient gradually decreasing from right to left. In female, ridges no. 1 and 5 most developed. Axis of orientation directed from right ventral to left dorsal side and inclined at about $60^{\circ}$ on sagittal axis in both sexes (Fig. 5D and $\mathrm{F}$ ).

\section{MALES}

Males are 5.2, $4.7 \mathrm{~mm}$ long and 110, 150 wide at mid-body, left ala included; cephalic vesicle 55, 60 long and 30, 35 wide; nerve ring, excretory pore and deirids situated at 190, 240; 290, -- and 300,--, from apex, respectively; oesophagus 410, 425 long.

Asymmetrical caudal bursa with right lateral lobe more developed and pattern of type 2-3 with tendency 2-2-1 (Fig. 5I). Right lobe: ray 4 curved dorsally at extremity, longer than ray 5 , ray 6 arising first from common trunk to rays 4-6. Left lobe: rays 4-6 arising at same level from common trunk. Rays 8 longer than dorsal ray and arising at its base. Dorsal ray deeply divided into two branches at level of arising of rays 8 , each branch giving rise to two small branches, rays 9 (external branches), longer than rays 10 (internal branches).

Spicules filiform, 350 long (in first specimen) with curved tips S-shaped. Gubernaculum 35 long and 30 wide (in second specimen). Genital cone not observed.

\section{FEMALES}

Females are 8.9, $6.9 \mathrm{~mm}$ long and 120, 140 wide at mid-body, left ala included; cephalic vesicle 60, 60 long and 32, 44 wide; nerve ring, excretory pore and deirids situated at 220, --; 350, -- and 340, 345 from apex, respectively; oesophagus 430, 420 long.

Monodelphic. Vulva situated at 110, 120 from caudal extremity. Vagina vera --, 28 long. Ovejector (observed only in first specimen) 250 long with vestibule 65 , sphincter 20 long and 33 wide, infundibulum 125 long. Uterus $1.4,1.3 \mathrm{~mm}$ long with 56 , 37 eggs at morula stage, 90 long by 50 wide on average, arranged in two rows except in distal part of uterus. Tail 56, 37 long with sharp extremity (Fig. $5 \mathrm{M})$.

\section{REMARKS}

The specimens described above, parasites of Rhabdomys pumilio were named Longistriata (L.) capensis by Ortlepp (1939). The characters of the synlophe, not described in transversal sections up to now, allow us to confirm that the species belongs to the genus Neoheligmonella, as proposed by Durette-Desset (1971).

Neoheligmonella capensis is distinguished from the other species of the genus by the S-shaped extremity of the spicules. However, the syntypes described here differ from the specimens described by Ortlepp (1939) in two characters, viz. the female tail, which is straight, and the dorsal ray, which is divided in the proximal part rather than at the distal one. This latter feature is usually diagnostic at specific level, and it is possible that the specimens studied here 


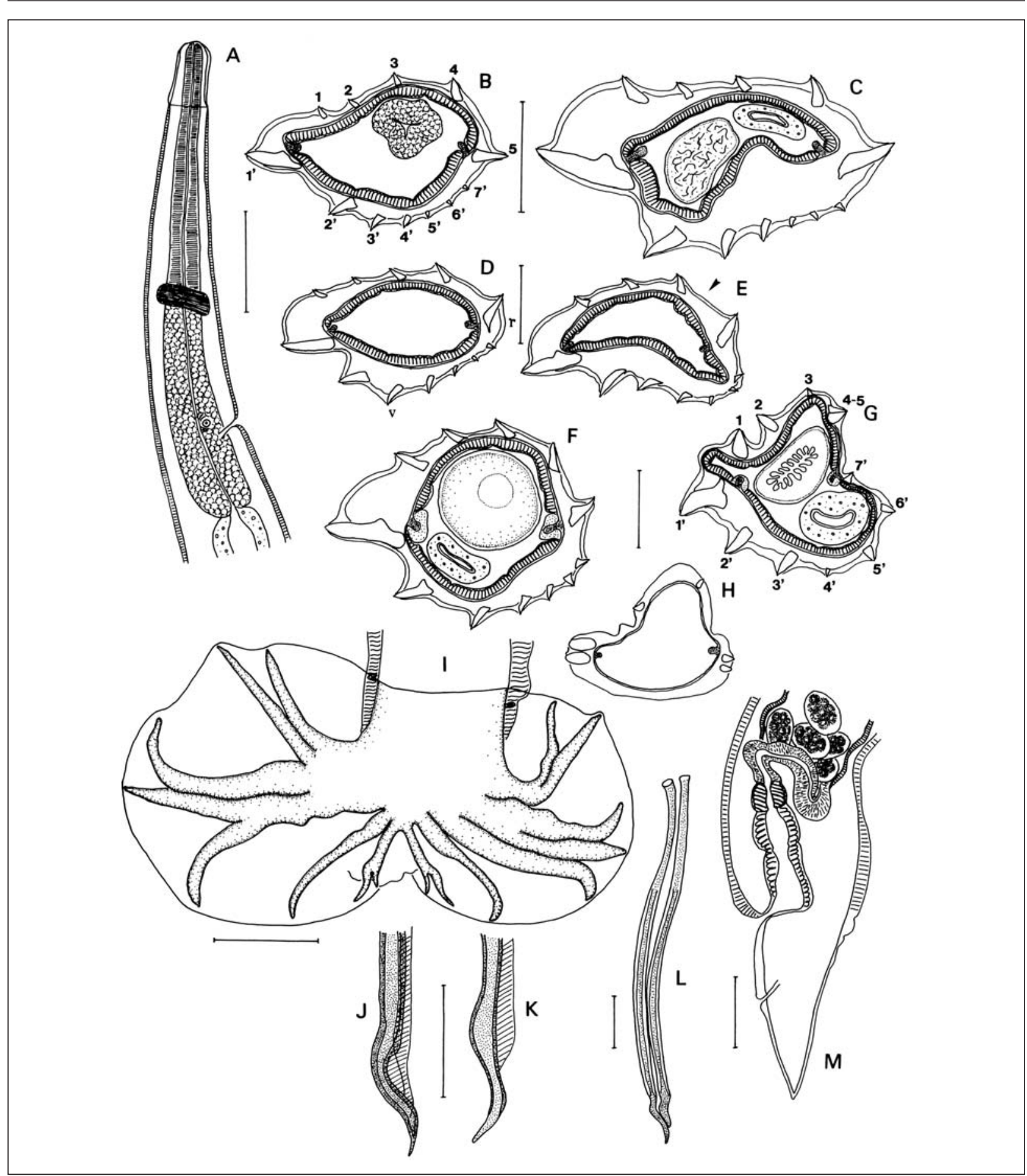

FIG. 5 Neoheligmonella capensis (Ortlepp, 1939) A, male, anterior part, right lateral view. B-H, synlophe in transverse sections of a male $(5.2 \mathrm{~mm}$ long) and a female $(8.9 \mathrm{~mm}$ long). B-E, male, B, at the level of the oesophago-intestinal junction, C, at the end of the anterior third of body, $\mathrm{D}$, at mid-body ( $3.1 \mathrm{~mm}$ from the apex), $\mathrm{E}$, at $1.3 \mathrm{~mm}$ anterior to the caudal bursa; $\mathrm{F}-\mathrm{H}$, female, $\mathrm{F}$, at mid-body (3.4 mm from the apex), $\mathrm{G}$, at the level of the infundibulum, $\mathrm{H}$, just anterior to the vulva. I, male, caudal bursa, ventral view. J, K, dissected tips of the spicules, J, right spicule, ventral view, K, left spicule, ventral view. L, spicules in situ, ventral view. M, female, posterior part, left lateral view

The ridges are numbered from left to right, no. 1-5 for the dorsal side, no. 1'-7' for the ventral side.

The arrows indicate the disappearance of the ridges. All the ridges are orientated as in Fig. 5D

Abbreviations: $r$, right side, $v$, ventral side

Scales: A, I, M: $100 \mu \mathrm{m}$; B-H, J-L: $50 \mu \mathrm{m}$ 
represent a new species. Since all the remaining characters are identical to those described for $N$. capensis, including the S-shaped extremity of the spicules, we prefer to assign the specimens, at least temporarily, to $N$. capensis, until such time more material becomes available.

In the genus Neoheligmonella, the caudal bursa is sub-symmetrical except in N. capensis and N. acomysi Durette-Desset \& Gibson, 1990 in which the right lobe is clearly more developed than the left one. This character distinguishes the genera $\mathrm{NeO}$ heligmonella and Heligmonina Baylis, 1928. In the latter, the asymmetry is always present with a more pronounced development of the left lobe.

\section{ACKNOWLEDGEMENTS}

We thank Prof. Joop Boomker for the loan of the material from the National Collection of Animal Helminths, Onderstepoort, South Africa.

\section{REFERENCES}

BAYLIS, H.A. 1928. On a collection of nematodes from Nigerian mammals (chiefly rodents). Parasitology, 20:280-304.
DESSET, M.-C. 1964. Les systèmes d'arêtes cuticulaires chez les Nématodes Héligmosomes. Etude de cinq espèces parasites de Rongeurs de La Maboké. Cahiers de La Maboké, 2:39-78.

DIOUF, M., BÂ, C.T. \& DURETTE-DESSET, M.-C. 1997. Deux nouveaux Nippostrongylinae (Nematoda-Trichostrongylina) parasites de Muridés du Sénégal. Zoosystema, 19:223-231.

DURETTE-DESSET, M.-C. 1971. Essai de classification des Nématodes Héligmosomes. Corrélation avec la paléobiogéographie des hôtes. Mémoires du Muséum national d'Histoire naturelle, nouvelle série, série A, Zooogie, 49:1-126.

DURETTE-DESSET, M.-C. 1985. Trichostrongyloid nematodes and their vertebrate hosts: reconstruction of the phylogeny of a parasitic group. Advances in Parasitology, 24:239-306.

DURETTE-DESSET, M.-C. \&. CHABAUD, A.G. 1981. Nouvel essai de classification des Nématodes Trichostrongyloidea. Annales de Parasitologie humaine et comparée, 56:297312.

DURETTE-DESSET, M.-C. \& GIBSON, D.I. 1990. Neoheligmonella acomysi $\mathrm{n}$. sp. (Trichostrongyloidea, Nippostrongylinae), parasite d'Acomys dimidiatus (Muridae) de Somalie. Sysematic Parasitology, 17:109-113.

MUSSER, G.G. \& CARLETON, M.D. 1993. Family Muridae, in Mammal species of the world. A taxonomic and geographic reference, edited by D.E. Wilson \& D.A.M. Reeder, Washington D.C: Smithsonian Institution Press.

ORTLEPP, R.J. 1939. South African helminths, Part VI. Some helminths, chiefly from rodents. Onderstepoort Journal of Veterinary Science and Animal Industry, 12:75-101. 